\title{
Comparison and analysis of maize grain commodity quality and mechanical harvest quality between China and the United States
}

\author{
Keru Wang ${ }^{1}$, Ruizhi Xie ${ }^{1}$, J un Xue ${ }^{1}$, Lirong Sun², Shaokun $\mathrm{Li}^{1 *}$ \\ (1. Institute of Crop Sciences, Chinese Academy of Agricultural Sciences/Key Laboratory of Crop Physiology and Ecology, \\ Ministry of Agriculture, Beijing 100081, China; \\ 2. Tongliao Agricultural and Livestock Product Quality and Safety Center, Tongliao 028000, Inner Mongolia, China)
}

\begin{abstract}
Maize is a bulk commodity in international agricultural product trading, and unified and standardized quality inspection standards are the basis of purchase and sales and other trading behaviors. China and the United States are the largest maize producers and consumers in the world, jointly accounting for more than $60 \%$ of the world's total production. In this research, the used data were from annual maize harvest quality reports released by the U.S. Grains Council in 2011-2019 and 2987 groups of mechanical grain harvest sample data collected by the Crop Cultivation and Physiology Innovation Team of the Chinese Academy of Agricultural Sciences in 2012-2019, this study compares the quality standards of commercial maize grain in China and the United States, the mechanical harvest quality (which affects the quality of the maize grain commodity), and the status quo of harvesting and storage processes in the two countries. Additionally, this study analyzes the differences in the formulation of mechanical harvest quality standards between China and the United States, as well as the reasons behind these differences, and recommends requirements for the formulation of quality standards for maize production technology and commodities that are in line with the economic conditions and maize-production conditions in China and in line with international standards in order to provide support for the industrialization of modern maize production in China.
\end{abstract}

Keywords: maize, quality standard, mechanical grain harvesting, test method

DOI: $10.25165 /$ j.ijabe.20221501.6099

Citation: Wang K R, Xie R Z, Xue J, Sun L R, Li S K. Comparison and analysis of maize grain commodity quality and mechanical harvest quality between China and the United States. Int J Agric \& Biol Eng, 2022; 15(1): 55-61.

\section{Introduction}

Maize (Zea mays L) is one of the most important crops in the world. Among the world's three major grain crops (wheat, rice, and maize), the total output of maize is the highest, accounting for more than $65 \%$ of the global production of food grains (e.g., maize, sorghum, millet). The output of the United States accounts for more than $40 \%$ of the international maize market; in 2019, the country's total output of maize was 347 million t (13 661 million bushels) and its export volume accounted for $28.1 \%$ of the global maize export volume. Additionally, maize has the largest planting area and largest total output of any crop in China, accounting for $90 \%$ of coarse grain output. The output and consumption of maize account for more than $20 \%$ of the world's total grain output and grain consumption, ranking second in the world ${ }^{[1,2]}$. The United States and China are both major producers and consumers of maize, and therefore have a great impact on the international maize commodity market ${ }^{[3,4]}$. Maize is a consistently popular investment in the international futures market due to its use in

\section{Received date: $2020-08-20 \quad$ Accepted date: $2021-03-26$}

Biographies: Keru Wang, $\mathrm{PhD}$, Professor, research interest: theory and technology of maize mechanization production, Email: wangkeru@caas.cn; Ruizhi Xie, PhD, Professor, research interest: maize physiology and ecology, Email: xieruizhi@caas.cn; Jun Xue, PhD, research interest: maize lodging resistance. Email: xuejun5519@126.com; Lirong Sun, Professor, research interest: quality and safety of agricultural and livestock products, Email: 13904751007@163.com.

*Corresponding author: Shaokun Li, PhD, Professor, research interest: physiology and ecology of maize high yield and high efficiency cultivation. Institute of Crop Sciences, Chinese Academy of Agricultural Sciences, No.12 Zhongguancun South Street, Haidian District, Beijing 100081, China. Tel: +86-10-82108891, Email: lishaokun@caas.cn. human nutrition, animal feed, and various industrial applications, as well as its high demand, long industrial chain, and seasonal fluctuation in production. As a bulk commodity in international agricultural trade, the standardization of maize quality is an inherent requirement of maize production, processing, storage and transportation, sales, and other industrial operation links. Unified and standardized quality inspection standards are the basis of purchase and sales and other transaction behaviors and are also closely related to the benefits of maize production ${ }^{[5,6]}$. This research compares and analyzes the differences in maize commodity quality standards in China and the United States in maize production and consumption, as well as the factors affecting the quality standards of the grain harvest. Additionally, it discusses the establishment of maize production technology and maize quality evaluation systems in line with international standards in order to improve the standardization and normalization level of maize production in China, promotes the sustainable development of mechanical grain harvesting technology, and improve the competitiveness of China's maize production in the international market ${ }^{[7-9]}$.

\section{Differences in maize grain commodity indicators}

2.1 Commercial maize grading standard in the United States

The official grain standard of the United States defines general indicators of grain quality (Code of Federal Regulations), which are mainly purity, color, broken maize and foreign material (BCFM), total damage rate (or complete grain rate), heat damage rate, number of small stone heads, grain moisture, and test weight (bulk density). Based on these and other indicators, maize is divided into five grades (Table 1). According to the U.S. Grains Council, high-quality maize is maize with a low and uniform grain moisture 
content, low stress crack and crushing rate, and low crushing sensitivity ${ }^{[10]}$.

Table 1 Maize quality grades in the United States

\begin{tabular}{ccccc}
\hline & & \multicolumn{3}{c}{ Maximum limits } \\
\cline { 3 - 5 } Grade & $\begin{array}{c}\text { Minimum test } \\
\text { weight } / \mathrm{g} \cdot \mathrm{L}^{-1}\end{array}$ & \multicolumn{2}{c}{ Damaged kernels $/ \%$} & Broken maize and \\
\cline { 3 - 5 } & & $\begin{array}{c}\text { Heat damaged } \\
\text { kernels }\end{array}$ & Total & foreign material $/ \%$ \\
\hline US No.1 & 720.8 & 0.1 & 3.0 & 2.0 \\
US No.2 & 695.1 & 0.2 & 5.0 & 3.0 \\
US No.3 & 669.4 & 0.5 & 7.0 & 4.0 \\
US No.4 & 630.7 & 1.0 & 10.0 & 5.0 \\
US No.5 & 592.1 & 3.0 & 15.0 & 7.0 \\
\hline
\end{tabular}

Note: US maize Grade is maize that: (a) does not meet the requirements for grades U.S. Nos. 1, 2, 3, 4, or 5; (b) contains stones with an aggregate weight in excess of $0.1 \%$ of the sample weight, two or more pieces of glass, three or more crotalaria seeds (Crotalaria spp.), two or more castor beans (Ricinus communis L.), four or more particles of an unknown foreign substance(s) or a commonly recognized harmful or toxic substance(s), eight or more cockleburs (Xanthium spp.) or similar seeds singly or in combination, or animal filth in excess of $0.2 \%$ per $1000 \mathrm{~g}$; (c) has a musty, sour, or commercially objectionable foreign odor; or (d) is heat-damaged or is otherwise of distinctly low quality.

Source: Code of Federal Regulations, Title 7, Part 810, Subpart D, United States Standards for Maize.

\subsection{Grading standard of commercial maize in China}

The grading and inspection standards of commercial maize in China have undergone several revisions, such as Maize GB1353-1999, Maize GB1353-2009, and Maize GB 1353-2018, with the latest being Maize GB 1353-2018 $8^{[4]}$. In the national compulsory standard, the test weight is the only index that is used to determine the maize grade. Table 2 describes the various maize quality grades in China and the indexes used to classify them. The difference between adjacent grades of the test weight has changed. The proportion of defective kernels is the limiting index and the proportion of severely moldy kernels is listed separately (Table 2). As shown in the table, commercial maize in China is also divided into five grades, however, as long as substandard maize meets regulations and health requirements, it is still permitted to be used as commercial maize and allowed to enter the markets (GB 1353-2018) [11]. $^{[1]}$.

Table 2 Maize quality grades in China

\begin{tabular}{ccccccc}
\hline Grade & $\begin{array}{c}\text { Minimum } \\
\text { test weight } \\
/ \mathrm{g} \cdot \mathrm{L}^{-1}\end{array}$ & $\begin{array}{c}\text { Defective } \\
\text { kernel rate } \\
/ \%\end{array}$ & $\begin{array}{c}\text { Impurity } \\
\text { rate/\% }\end{array}$ & $\begin{array}{c}\text { Severely } \\
\text { moldy } \\
\text { kernels/\% } \%\end{array}$ & $\begin{array}{c}\text { Grain } \\
\text { moisture } \\
\text { content/\% }\end{array}$ & $\begin{array}{c}\text { Color } \\
\text { and } \\
\text { smell }\end{array}$ \\
\hline No.1 & 720.0 & $\leq 4.0$ & 1.0 & 2.0 & $\leq 14.0$ & Normal \\
No.2 & 690.0 & $\leq 6.0$ & 1.0 & 2.0 & $\leq 14.0$ & Normal \\
No.3 & 660.0 & $\leq 8.0$ & 1.0 & 2.0 & $\leq 14.0$ & Normal \\
No.4 & 630.0 & $\leq 10.0$ & 1.0 & 2.0 & $\leq 14.0$ & Normal \\
No.5 & 600.0 & $\leq 15.0$ & 1.0 & 2.0 & $\leq 14.0$ & Normal \\
Off-grade & $<600$ & -- & 1.0 & 2.0 & $\leq 14.0$ & Normal \\
\hline
\end{tabular}

Source: GB1353-2018, China National Standard for Maize.

\subsection{Differences in maize grade indexes between China and the United States}

Comparing the maize grading standards of China and the United States, it can be found that, although the grain test weight, breakage rate, and impurity rate are used to determine the maize grade in both of the two countries, there are also obvious differences between the two grading systems. Firstly, there are different grading levels. Secondly, there are different definitions for each grading index. Thirdly, there are different quantitative standards for each grading level and index. In China, grain breakage is mainly quantified using the defective kernel rate. Defective kernels include broken kernels, but also include kernels with excessively high moisture content, severely moldy kernels, and kernels with an unacceptable color and/or smell. In the United States, the examination of kernel breakage is divided into two parts: one is broken maize and foreign material (BCFM), and the other is damaged kernels. Damaged kernels mainly refer to grain damage caused by post-harvest transportation, drying, and storage, including kernel breakage. In terms of impurity indicators, the United States does not list these indicators separately, while China does ${ }^{[12]}$.

In the standards of both China and the United States, test weight is used as a general index to reflect the overall quality of maize and is also an important index to measure the processing and feeding quality of maize. The main factors affecting test weight are differences in grain structure, grain maturity, and grain moisture content, physical damage to grains, impurities, grain size, etc. At a specific grain moisture content, maize with a high test weight is considered to be high-quality. Meanwhile, for the same weight of maize, a high test weight means that less space is required for storage.

2.4 Differences in test standards between China and the United States regarding the breakage rate and impurity rate of commercial maize

In the process of the harvesting, transportation, drying, and storage of maize, the quality of maize commodities will be affected by various operations, with the breakage rate and impurity rate being especially easily affected. In the United States, the requirements and determination methods for maize breakage rate and impurity rate are in accordance with U.S. Food Standard 810 established by the US. In Grain Standards Act (810.401-810.405), the broken maize fraction and the impurity fraction are defined. In this standard, broken maize (BC) is defined as maize or any other material (such as weed seeds) that is small enough to pass through a $4.76 \mathrm{~mm}$ round-hole sieve and too large to pass through a $2.38 \mathrm{~mm}$ round-hole sieve. Foreign material (FM) is any non-maize material that is too large to pass through a $4.76 \mathrm{~mm}$ round-hole sieve as well as all fine material that is small enough to pass through a $2.38 \mathrm{~mm}$ round-hole sieve. Meanwhile, broken maize and foreign material (BCFM) is defined as all matter that passes readily through a $4.76 \mathrm{~mm}$ round-hole sieve and all matter other than maize (e.g., weed seeds) that remains in the sieve after sieving according to procedures prescribed in the instructions of the Federal Grain Inspection Service (FGIS). A schematic diagram of the detection of broken maize and foreign material in the United States is shown in Figure 1.

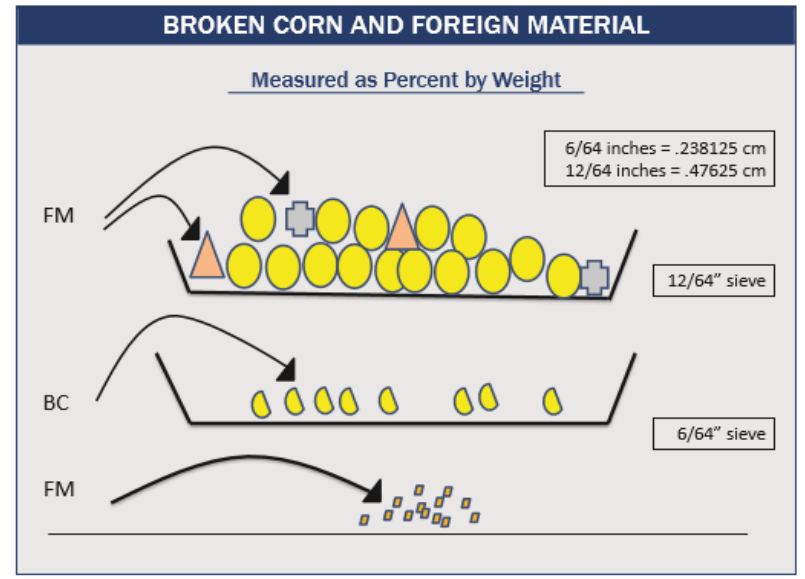

Source: U.S. Grains Council, Maize Harvest Quality Report 2019/2020 [13]

Figure 1 Schematic diagram of the detection of broken maize (BC) and foreign material (FM) in the United States 
BCFM is an indicator of the amount of clean, mechanically sound maize that is available for feeding and processing. Higher levels of BCFM in farm-originated samples generally stem from harvesting practices or the presence of weed seeds in the field. BCFM levels normally increase during drying and handling, depending on the methods used and the soundness of the kernels.

In the United States' maize classification system, the definition of broken grain is mainly based on the size of the maize kernels, and usually includes a very small proportion of non-maize materials (conforming to BC size, that is, the fraction which passes through a $4.76 \mathrm{~mm}$ round-hole sieve and does not pass through a $2.38 \mathrm{~mm}$ round-hole sieve). Compared with whole maize kernels, broken maize kernels are more vulnerable to diseases and insect pests and are more difficult to transport and store. Impurities or FM have a great impact on the quality of maize, thus reducing its feed or processing value. Furthermore, the moisture content of impurities is usually higher than that of maize grain, which may lead to maize deterioration in the storage and transportation process.

The Chinese national standard Maize GB1353-2018 includes the concept of defective kernels in its maize quality and quality grading, while the part of broken maize is included in defective kernels and impurities. In this standard, "defective kernels" refers to defective and damaged maize kernels, which still have economic value, including infested kernels, diseased kernels, damaged kernels, germinated kernels, moldy kernels, and heat-damaged kernels. Among them, "infested kernels" refers to kernels that contain wormholes or tunnels, "diseased kernels" refers to grain with disease spots on the grain surface and injury to the embryo or endosperm, and "heat-damaged" refers to grain with significant discoloration or damage due to natural heating or intentional drying; natural heat damage refers to significant discoloration of the embryo or endosperm due to excessive respiration during storage, while drying heat damage refers to significant discoloration of the epidermis, embryo, or endosperm, or grain deformation or bulging, caused by heating. Meanwhile, "damaged kernels" refers to kernels that are broken so as to lose more than $1 / 5$ of their original volume, and "impurities" refer to substances other than maize grain and maize grain with no economic value, including "substances under sieve", inorganic impurities, and organic impurities; among them, "substances under sieve" refers to substances that pass through a $3.0 \mathrm{~mm}$ round-hole sieve, "inorganic impurities" refers to particles of inorganic substances, such as soil, sand, brick, and tiles, and "organic impurities" refers to maize grains with no economic value, kernels of other kinds of grains, weed seeds, and other organic substances.

In conclusion, the detection of maize grain crushing rate and impurity rate in the United States is based on the grain size, while the detection of maize crushing rate and impurity rate in China is based on the whole grain and other non-grain material. For slightly damaged maize grains, which are considered broken grain in Chinese standard, they may be complete grain according to American standard. For impurity detection, the diameter of round-hole sieve in China was larger than that in the United States. Therefore, the testing standards for maize grading in China are high than those in the United States.

\section{Quality comparison of mechanically harvested maize grain in China and the United States}

Harvesting is the key process in the transformation of maize in the field to a commodity. The quality of harvest determines the quality of the maize commodity to a large extent. The United
States achieved a mechanical maize grain harvesting rate of $100 \%$ in the 1970s. With the improvement of maize varieties, the continuous improvement of grain harvesting machinery, and the construction and improvement of drying and storage facilities, the quality of maize harvesting in the United States has greatly improved and has reached a high level ${ }^{[14-16]}$. Although more than $75 \%$ of China's maize harvesting is performed mechanically, as of 2019 , the majority of this mechanical harvesting was mechanical ear harvesting, whereas mechanical grain harvesting technology was used in less than $10 \%$ of the maize grain harvesting in China. In China, a significant amount of maize still needs to go through the process of mechanical ear picking and drying, which greatly limits the improvement of the quality of maize commodities. With the development of the social economy, new management styles and large-scale planting, maize mechanical harvesting technology is predicted to become the mainstream of modern maize production technology in China ${ }^{[17]}$.

\subsection{Quality of mechanically harvested maize grain in the} United States

Since 2011, the U.S. Grains Council has collected grain samples and analyzed the quality of harvested maize from the 12 states with the largest maize production and export volume in the maize harvest season, and has issued annual maize harvest quality reports which provide the basis for maize market transactions in the United States (https://grains.org/corn_report). According to the analysis of the harvest quality report data, the average broken maize rate of the harvest samples in the United States between 2011 and 2019 was $0.62 \%$; the average percentage of FM, grain moisture, total damage, stress cracks, and whole kernels were $0.22 \%, 16.41 \%, 1.56 \%, 5.43 \%$, and $93.11 \%$ (Table 3 ). The above indexes changed little throughout the observation period, which indicates that the mechanical maize grain harvesting technology in the United States is mature.

Table 3 Statistics of main indexes of the quality of mechanical maize grain harvesting in the United States from 2011 to 2019

\begin{tabular}{cccccccc}
\hline Year & $\begin{array}{c}\text { No. of } \\
\text { samples }\end{array}$ & $\begin{array}{c}\text { Grain } \\
\text { moisture } \\
\text { content/\% }\end{array}$ & BC/\% & FM/\% & $\begin{array}{c}\text { Total } \\
\text { damage } \\
/ \%\end{array}$ & $\begin{array}{c}\text { Stress } \\
\text { cracks } \\
/ \%\end{array}$ & $\begin{array}{c}\text { Whole } \\
\text { kernels } \\
/ \%\end{array}$ \\
\hline $2011-2019$ & 5391 & $16.41 \pm 0.83$ & $\begin{array}{c}0.61 \\
\pm 0.12\end{array}$ & $\begin{array}{c}0.22 \\
\pm 0.06\end{array}$ & $\begin{array}{c}1.56 \\
\pm 0.69\end{array}$ & $\begin{array}{c}5.43 \\
\pm 2.28\end{array}$ & $\begin{array}{c}93.11 \\
\pm 1.81\end{array}$
\end{tabular}

Source: https://grains.org/corn_report. $\quad$ BC: broken maize; FM: foreign material.

\subsection{Quality of mechanical maize grain harvesting in China}

China's mechanical maize grain harvesting technology is in a period of rapid development ${ }^{[18]}$. The 2987 groups of field mechanical maize grain harvest samples obtained from 21 provinces and cities of China between 2012 and 2019 were analyzed $^{[19]}$. The grain moisture content at harvest had an average value of $25.91 \%$ (Table 4 ); the crushing rate had an average value of $7.96 \%$, which was 2.96 percentage points higher than the Chinese national standard of 5\%; the average impurity rate was $1.18 \%$, not exceeding the national standard of $3 \%$. According to the United States grain quality evaluation index, the average whole kernels rate was $92.04 \%$, which is slightly lower than the average value for the United States, however, the variation range was larger than that in the United States data.

Table 4 Statistics of the quality of mechanical maize harvesting in China in 2012-2019 ${ }^{[19]}$

\begin{tabular}{cccccc}
\hline Year & $\begin{array}{c}\text { No. of } \\
\text { samples }\end{array}$ & $\begin{array}{c}\text { Grain moisture } \\
\text { content } / \%\end{array}$ & BC/\% & FM/\% & $\begin{array}{c}\text { Whole kernels } \\
/ \%\end{array}$ \\
\hline $2012-2019$ & 2987 & $25.91 \pm 5.03$ & $7.96 \pm 4.81$ & $1.18 \pm 1.53$ & $92.04 \pm 5.03$ \\
\hline
\end{tabular}


3.3 Differences of methods and standards for determination of mechanical maize grain harvesting quality in China and the United States

There are great differences between the quality indexes of mechanical maize harvesting that are used in China and the United States. As both the broken grain fraction and the impurity fraction are closely related to the crushing and impurities produced during harvest, the Chinese quality index gives larger importance to the broken maize rate and impurity rate in the mechanical harvesting of maize grain. In China, the method to determine the broken maize rate and impurity rate in the field is based on the method specified in "GB 21961-2008 Maize Harvester, Test Method". This method is described in the following: In the test area, take $2 \mathrm{~kg}$ of threshed grains from the grain tank of the harvester and pick out the grains with machine damage, obvious cracks, and broken skin. The weight percentage of damaged grains is taken as the broken maize rate. The method to determine the impurity content is as follows: In the test area, take $2 \mathrm{~kg}$ of threshed grains from the grain tank of the harvester and pick out impurities. Weigh these impurities. The weight percentage of impurities in the sample is taken as the impurity content ${ }^{[6,12]}$. However, the standard does not give a more detailed description of damaged grains than "machine damage grains, grains with obvious cracks and broken skin". In the actual operation of broken maize grain sorting, the principle of identifying broken maize kernels is as follows: as long as a particle is a part of maize grain, including intact grains with a broken seed coat, incomplete grains, and broken parts of a grain; meanwhile, impurities are defined as the non-maize-grain fraction of the sample, including maize stem, leaf, dried silks, cob, soil, non-maize dust, and other material. The quality standards of broken maize grain rate and impurity rate are based on the provisions of "GB/T 21962-2008 Maize Harvester, Technical Conditions". For mechanical maize harvesting, the broken maize rate should not exceed $5 \%$ and the impurity rate should not exceed $3 \%$. It can be seen from this that the broken maize part of the determination includes the broken part of "defective kernels" specified in "GB 1353-2018 Maize", as well as the maize grain part of impurities with no use-value, especially the part under the sieve.

In the United States, the maize harvest sample that is used for quality analysis is collected from the elevator or bin; that is, after the harvested maize is transported back from the field and unloaded into the elevator or bin, the sample is taken from the elevator or bin with a sample cutter within the specified sampling time; the broken maize rate and impurity rate (FM) of the sample are determined using sieves with different apertures. The test standard is the official United States standard for grain (Part 810) according to the United States grain standard law. In China, the broken maize fraction includes the BC fraction of BCFM defined in the United States standard and the FM fraction that passes through a $2.38 \mathrm{~mm}$ round-hole sieve, as well as the kernels that fail to pass through a $4.76 \mathrm{~mm}$ round-hole sieve is recognized as whole kernels by the United States standard, including the kernels with a cracked seed coat, missing angle of kernels, or obvious crack. Therefore, the broken maize rate determined using Chinese standard is stricter than that determined using the United States standard. In the United States, the definition of impurities does not include the non-maize part passing through a $4.76 \mathrm{~mm}$ round-hole sieve, that is, the impurity standard determined by us is stricter than that in the United States. Additionally, unlike in the United States standard, the kernel samples in China were directly taken from the harvester grain tank, and can therefore more accurately reflect the quality of mechanical grain harvesting.

Although there are some problems in the methods and standards that are used in the United States to determine the impurity rate and crushing rate, these methods and standards are objective, labor-saving, fast, convenient for mechanized batch operation, and have good repeatability. Although the methods used in China for the determination of the broken maize rate and impurity rate are accurate, it is difficult to eliminate subjective influence when performing manual sorting. Additionally, human fatigue can affect detection accuracy. Furthermore, these methods have additional disadvantages such as labor-intensiveness and low efficiency, and accordingly, they need to be improved by adopting the detection methods that are used in the United States.

\subsection{Comparison of maize harvest loss between China and the United States}

Harvest loss is a key index that is used to evaluate the quality of harvest operations and is also an important factor influencing the willingness of farmers to adopt mechanical harvesting technology. Harvest loss includes grain loss and ear loss. In the United States, the standard for the mechanical harvest loss rate of maize is not more than $3 \%$ of the yield ${ }^{[20]}$, while in China the equivalent standard is not more than $5 \%$ of the yield $(\mathrm{GB} / \mathrm{T} 21962-2008)^{[21]}$. The analysis of the 2987 groups of mechanically harvested maize grain samples from 2012-2019 reported that the average harvest loss is $345.15 \mathrm{~kg} / \mathrm{hm}^{2}$ (range: $0-9288.45 \mathrm{~kg} / \mathrm{hm}^{2}$ ), which is equal to $3.54 \%$ of the yield (range: $0-58.55 \%)^{[19]}$, which is less than the Chinese standard but slightly higher than the United States standard ${ }^{[22]}$.

The main maize-producing states in the United States have their own methods for measuring the mechanical harvest loss of maize, however, these methods are generally similar. In Missouri, harvest losses are determined by counting the number of full-size ears (i.e., those which weigh around $340 \mathrm{~g}$ ) or the equivalent weight in smaller ears found in an area of $0.004 \mathrm{hm}^{2[23]}$. Each full-size ear represents a loss of about $62.77 \mathrm{~kg} / \mathrm{hm}^{2}$. Count the kernels per 10 square feet $\left(0.929 \mathrm{~m}^{2}\right)$ to determine kernel losses. $0.0929 \mathrm{~m}^{2}$ equals a loss of $62.77 \mathrm{~kg} / \mathrm{hm}^{2}$. The length of maize rows for this $0.004 \mathrm{hm}^{2}$ or $0.929 \mathrm{~m}^{2}$ varies with the row width and the number of rows covered by the maize header. Count the loose kernels on the ground and those still attached to the threshed cobs in an area of 10 square feet in each row behind the combine to determine the total kernel loss. At present, most of the harvest loss investigation methods adopted in China refer to the DB41/T 1409-2017 technical specifications for the measurement of maize grain yield in mechanical harvesting ${ }^{[18,24-26]}$. Randomly select sample points in the harvested plot. The length of each sampling area is $2 \mathrm{~m}$ and the width is the width of the maize header that is used. All of the fallen ears and grains in the sample area are collected, the number of ears is recorded, the ears are hand shelled, the lost ears and grains are weighed, respectively, and the weight of lost ears and grains are calibrated to a moisture content of $14 \%$. According to the yield data of the harvested field, the harvest loss from ear falling, the harvest loss from grain falling, and the total harvest loss rate were calculated.

\section{Harvest time and storage mode of maize}

Previous studies have shown that the harvest time and the moisture content of maize grains at harvest time are the key factors affecting the quality of mechanically harvested maize grain ${ }^{[18,25-27]}$. There are great differences between the studied harvest quality data from China and the United States. From the sample data of maize harvested in the United States from 2011-2019, although the 
average moisture content of grains in the harvest period fluctuates to a certain extent due to the climate and other factors, it is basically stable at around $16 \%$. For example, in $2017,36.2 \%$ of the samples had a grain moisture content at harvest of more than $17 \%$, which is related to the increased rainfall in the harvest season; the lowest annual average moisture content of $15.3 \%$ occurred in 2012, which was a particularly dry year, while the highest annual average moisture content of $17.7 \%$ occurred in 2013 , which was a cold and rainy year (Figure 2). Meanwhile, the average grain moisture content of the 2987 harvest samples obtained in China from 2012-2019 was 25.9\%; the annual average grain moisture content ranged from $23.88 \%-27.28 \%$, with the lowest grain moisture content being $10.63 \%$ and the highest being $44.60 \%$. That is, the overall average value in China is nearly 10 percentage points higher than that of the United States. Even though the average grain moisture content in China has declined in recent years, its value is still far higher than the average value in the United States (the value in China was $24.85 \%$ in 2018 and $23.88 \%$ in 2019).
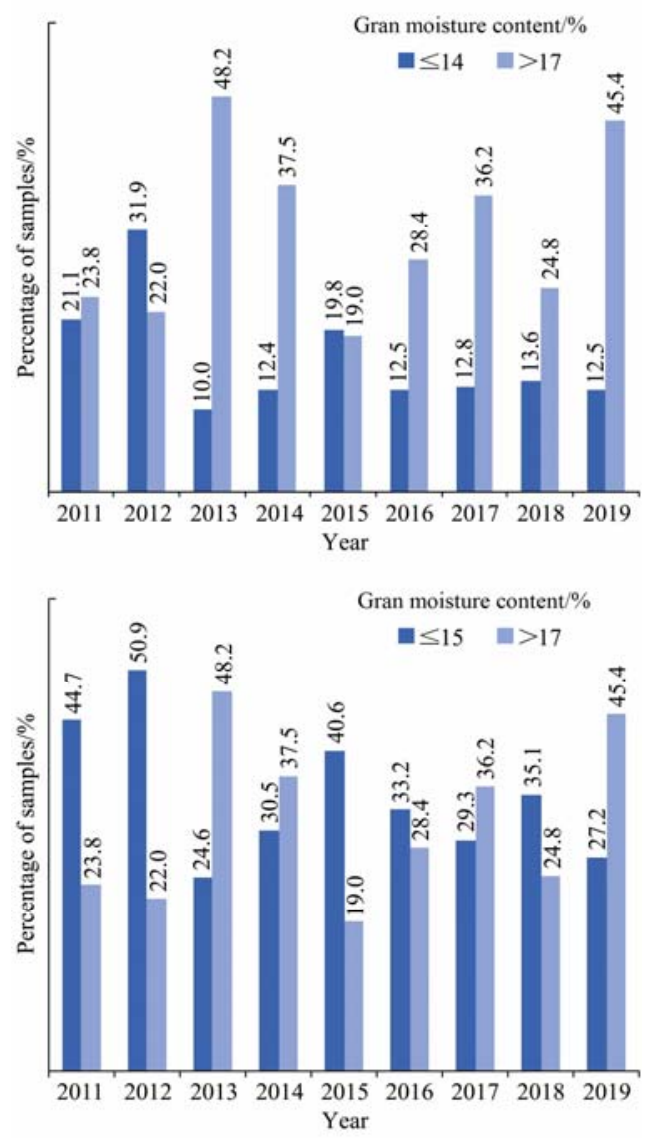

Note: Data source: U.S. Grains Council Maize Harvest Quality Report 2019/2020.

Figure 2 Distribution of the grain moisture contents of maize harvest samples in the United States

Generally, it is considered that the highest acceptable value of maize grain moisture content for safe storage is 14\% (GB $1353-2018)^{[11]}$. In the United States, a maize grain moisture content of $17 \%$ is usually used as the lower limit to apply drying treatment; that is, when the moisture content of harvested maize grain is higher than $17 \%$, drying is necessary. However, drying increases the production cost, increases the vulnerability of maize grain, and reduces the quality of the maize commodity. Therefore, in order to reduce the drying cost and improve the quality of the maize commodity, many maize varieties with high grain dehydration rates and suitable for mechanical grain harvest were bred by companies, research institutes and universities. In addition, maize is generally harvested 2-4 weeks after physiological maturity in the United States. During maize grain dehydration via plant standing in the field after physiological maturity, the risk of lodging increases due to stalk senescence or stalk rot. Therefore, the maize varieties have higher lodging and disease resistance after physiological maturity in the United States.

In the United States, when the moisture content of maize grain falls below $17 \%$ can a large amount of maize be harvested. After harvest, the maize grain is directly stored in grain bins and the moisture content is reduced to the standard storage value through ventilation. In farms in the United States Maize Belt, the average temperature is about $0^{\circ} \mathrm{C}$ when a large amount of maize is harvested in the middle and last $10 \mathrm{~d}$ of October, and the maize storage facilities used in the farms are mostly cylindrical metal bins with ventilation equipment. With good management, the grain moisture content can be reduced to less than $17 \%$, at which level the grain can be safely stored until April or May of the following year. Only when the moisture content of the grain exceeds $17 \%$, it can be heated and dried to reduce the moisture content to $15.5 \%$. In the United States, the proposed upper value of grain moisture content for safe storage is $25 \%$, however only for a storage temperature below $0^{\circ} \mathrm{C}$, often is at $-1.1^{\circ} \mathrm{C}$, under ventilation. Because the grain moisture content is higher (e.g., 28\%), maize grains will freeze, affecting the mobility of maize. In the United States, the harvesting, loading and unloading, warehouse storage, and turning and ventilation of maize are all automated, and the freezing of grain is not conducive to these operations ${ }^{[27]}$.

The high moisture content of harvested maize grain in China is related to the ecological conditions of the production area, variety selection, planting mode, production habits, and so on. The spring maize area in Northwestern China has good heat conditions and natural air drying. The practices of farmers in the United States can be used for reference to achieve low grain moisture content at harvest in $\mathrm{China}^{[28]}$. In the spring maize area in Northeastern China, the grain drying time while standing in the field can be appropriately extended and the moisture content of grains at harvest can be reduced in order to reduce the storage loss and drying cost ${ }^{[29]}$. However, in the Huanghuaihai summer maize region, since this region employs a planting system in which two crops are planted in one year, the time interval between harvesting and sowing is very short, and additionally, farmers tend to vacate the land for the following wheat crop. In this region, the maize harvest time is too early and the grain moisture content at harvest time is too high $^{[30]}$. Additionally, in the Huanghuaihai summer maize region, the yield of toxin in the period from harvest to feed processing will be increased due to the high grain-crushing rate in this region; therefore, the requirements for drying conditions are more stringent in the Huanghuaihai summer maize region. Due to the limited storage and drying conditions, the loss of maize after harvest is large in China, which has a great impact on the quality of maize commodities. This situation needs to be continuously improved by improving the industrial chain. Maize toxin consists of two parts: one is produced before harvest and the other is produced after harvest and before processing. The toxin level of maize grain before harvest is mainly reduced by planting varieties that are resistant to ear rot and kernel rot, while the toxin level after harvest is mainly reduced by improving harvest quality, drying in time to avoid grain deterioration, and safe storage.

\section{Discussion}

Quality standards are the technical basis for evaluating product quality as well as the technical standard for organizing product production and processing, quality inspection, grading, purchase 
and acceptance, and the negotiating trade. The establishment of reasonable standards for agricultural products is not only the benchmark and guiding force for modern agricultural standardized production but also guarantees the improvement of the quality and efficiency of agricultural production. At present, compared with more advanced countries, there is still a certain gap between the quality of Chinese agricultural products and the requirements of consumers $^{[31]}$.

Maize has a wide range of uses, which can be roughly divided into three kinds: human nutrition, animal feed, and industrial raw materials. Different quality standards are applied for different uses of maize. For example, in the animal breeding industry, high-quality maize refers to maize that can promote animal health and cause animals to gain the most weight. Meanwhile, in the starch processing industry, high-quality maize refers to that with the largest starch output, and there are differences in quality due to differences in the processing technology. Previous research has found that, when the maize drying or dehydration temperature exceeds $60^{\circ} \mathrm{C}$, maize grain will produce gels, and with each increase of $5^{\circ} \mathrm{C}$ the starch content can be reduced by $1 \%{ }^{[32]}$. Japan is more willing to use South African maize since this maize is $100 \%$ dehydrated in the field and therefore does not require drying. However, $85 \%$ of Japan's maize (about 18 million t/a) is imported from the United States. In the United States, low-temperature drying or field drying is adopted and the crushing rate is strictly controlled ${ }^{[33]}$. In China, maize is mainly used for feed processing (about $60 \%$ of the maize produced in China is used for feed, while about $30 \%$ is used for industrial processing), especially in the Huanghuaihai region (which cannot produce enough maize to meet its own demand). In feed processing, the maize toxin level is more important than the broken maize rate. As a country with large maize production and demand, the quality of maize (both the internal quality and the visual quality) in China is related to national food security and the economic benefits of the producers. Establishing and improving a unified maize quality standard can, on the one hand, provide producers and users with a relatively stable reference system, and, on the other hand, can also allow national institutions to test imported agricultural products based on this standard. In international trade, China occupies a favorable position and maintains its own legitimate interests. As a developing country, there is a large gap between China's maize production and those of more advanced countries. Scientific analysis and the rapid development of relevant technologies can help to reduce this gap. In terms of maize mechanical grain harvesting technology, which affects the quality of the maize commodity, the United States has developed and promoted its mechanical grain harvesting technology through many years of experience. Due to the high moisture content of grains at the time of harvesting, the mechanical damage to grains is large and the drying cost is high ${ }^{[15,33]}$. Between 1984 and 1987, the United States' maize exports dropped significantly ${ }^{[34,35]}$. A large amount of research has been carried out on the mechanical damage and breakage of grains, which has promoted the selection of breakage-resistant varieties. Through the measures of variety improvement, early ripening, prolonging grain dehydration time, improving grain harvesting machinery, harvesting under suitable grain moisture content, natural ventilation and drying of maize, reducing the duration and intensity of maize treatment during the period between post-harvest and sale, the high moisture content of grains and the poor quality of mechanical grain harvesting in the United States have been gradually improved ${ }^{[36,37]}$, thus improving the position of the United States in the international maize trade. In this paper, through the comparison of the present quality of mechanically harvested maize grain in China and the United States, it was shown that the average and variation range of the grain breakage rate and impurity rate are much higher in China than in the United States. Determining ways to reduce the grain moisture content, grain breakage rate, and impurity rate at harvest is key to improving the quality of mechanical grain harvesting in the future.

Market demand determines the direction of production and development. Only by organizing production and management according to standardization can market-recognized products be provided. The International Organization for Standardization (IOS) has formulated relevant agricultural standards since 1974 and has a complete quality standard system. Developed countries have widely used a series of standards formulated by the IOS, however have also developed their own national standards, industrial standards, and organizational standards in line with the international standards, which provides a good reference for China. Mechanical maize grain harvesting technology is the direction of the development of modern maize production. In the future, there are plans to formulate and implement a set of quality and technical standards for mechanically harvested maize grain, as well as quality inspection systems, which are in line with China's national conditions and international standards. These will not only make full use of technical regulations, standards, and qualified evaluation procedures and promote the standardization of the maize industry, but will also promote the development of mechanical maize harvesting technology and improve the market competitiveness of China's maize using scientific and technological approaches.

It is believed that China should emulate the United States' practice of testing and issuing annual reports of maize harvest quality. In order to increase the share of the United States' agricultural products in the international market, every year since 2011, the U.S. Grains Council (founded in 1960) has released an annual maize harvest quality report to inform international purchasers of the initial quality of the country's commercial maize in the production area when it enters the circulation channel. These reports include data from the 12 states with the largest production and export volume in the United States and are based on grain samples collected at the time of maize harvest. Additionally, they provide the basis for transactions in the United States maize market and have helped to realize the continuous improvement of maize harvest quality from the perspective of market demand. The mechanical maize harvesting technology in China is in a stage of rapid development. It is of great significance to research and promote mechanical maize harvesting technology and maize market trade by performing annual maize harvest quality monitoring and releasing harvesting quality reports.

\section{Conclusions}

The results of a large number of field investigations show that the average grain moisture during mechanical grain harvest of maize is $25.9 \%$, which is basically consistent with the provisions of China's standard for mechanical grain harvest of maize that the grain moisture should be equal to or lower than $25 \%$, But it is much higher than the grain moisture of American maize at harvest (16\% on average). Therefore, the high grain moisture at harvest is the main reason why the crushing rate of maize grain in China is higher and the whole kernels rate is lower than that in the United States. It is also the main reason why it is easy to mildew and further reduce the quality after harvest, and it is also one of the 
reasons why it must be dried after harvest to increase the production cost. Therefore, it can be concluded that low moisture Mechanical harvesting of maize under the condition of (below 20\%) is the main direction of grain maize production in China. This production goal can be defined as soon as possible, which can be arranged and arranged in advance, so as to avoid detours and reduce the waste of capital and time. However, to achieve this production goal, multiple links such as maize breeding, cultivation and farming, harvesting and drying machinery, maize grain of purchase and storage, standard formulation and policy guidance are needed, this can only be achieved through joint cooperation. At the same time, research, experiment and demonstration should be carried out in qualified areas, such as the south of Northwest spring maize area and northeast spring maize area, so as to accumulate corresponding technology and experience and guide the transformation of maize production mode.

\section{Acknowledgements}

This study was supported by the National Key Research and Development Program of China (Grant No. 2016YFD0300101; No. 2016YFD0300110), the National Natural Science Foundation of China (Grant No. 31371575), the China Agriculture Research System (CARS-02-25), and the Agricultural Science and Technology Innovation Project of the Chinese Academy of Agricultural Sciences.

\section{[References]}

[1] Market Early Warning Expert Committee of the Ministry of Agriculture and Rural Areas. China Agriculture Outlook Report (2018-2027). Beijing: China Agricultural Science and Technology Press, 2018; 202p. (in Chinese)

[2] National Bureau of Statistics. China Statistical Yearbook. Beijing: China Statistical Press, 2015-2019. (in Chinese)

[3] Lu J, Lin Y. Fluctuation characteristics of international corn price and its impact on China's food security. Manage World, 2013; 5: 76-87. (in Chinese)

[4] Wu T, Jiang N, Xi Y, Jiang X. Characteristics and prospects of China's corn trade in the new era. Agr Outlook, 2018; 2: 74-78. (in Chinese)

[5] Tang X, Guo L, Wang M, Mao X, Guo L. Research and enlightenment of UN/ECE agricultural product quality standardization. World Agric, 2011; 12: 38-43. (in Chinese)

[6] $\mathrm{Xu} \mathrm{W,} \mathrm{Jia} \mathrm{J.} \mathrm{The} \mathrm{impact} \mathrm{of} \mathrm{technical} \mathrm{barriers} \mathrm{to} \mathrm{trade} \mathrm{in} \mathrm{agricultural}$ products on China's exports: An empirical study from the perspective of free trade zone. Econ J, 2013: 1: 33-37. (in Chinese)

[7] Guo L, Tang X, Mao X. Quality standards of agricultural products in China and countermeasures. China Food Nutr, 2017; 23: 11-14. (in Chinese)

[8] Xu X, Ma F, Li D, Zhang X. Analysis of problems and countermeasures in the construction of China's agricultural standard system. Qual Safety Agr Prod, 2017; 2: 36-38. (in Chinese)

[9] Wang K R, Xie R Z, Ming B, Hou P, Xue J, Li S K. Review of combine harvester losses for maize and influencing factors. Int J Agric \& Biol Eng, 2021; 14(1): 1-10.

[10] Sarwar G, Litchfield B, Coaldrake P. Effect of drying and tempering on stress crack development and breakage susceptibility in selected corn hybrids. St. Joseph, Mich, USA: ASAE, 1989; Paper No. 89-6524.

[11] GB 1353-2018. Corn. Issued by the State Administration of Market Supervision/China National Standardization Administration, 2018.

[12] Huang Z F, Xue J, Ming B, Wang K R, Xie R Z, Hou P, et al. Analysis of factors affecting the impurity rate of mechanically-harvested maize grain in China. Int J Agric \& Biol Eng, 2020; 13(5): 17-22.

[13] Report on corn harvest quality in the United States U.S. Grain Council. 2019/2020 Corn harvest quality report. 2020. https://grains.org/corn report/corn-harvest-quality-report-2019-2020/. Accessed on [2020-01-01].

[14] Waelti H. Physical properties and morphological characteristics of maize and their influence on threshing injury of kernels. $\mathrm{PhD}$ dissertation. Ames: Iowa State University, 1967; 150p.
[15] Waelti H, Buchele W F. Factors affecting corn kernel damage combine cylinders. Transactions of the ASAE, 1969; 12: 55-59.

[16] Dutta P K. Effects of grain moisture, drying methods, and variety on breakage susceptibility of shelled corns as measured by the Wisconsin Breakage Tester. PhD dissertation. Ames: Iowa State University, 1986; 216p.

[17] Nanjing Institute of Agricultural Mechanization, Ministry of Agriculture and Rural Affairs. China agricultural mechanization yearbook. Beijing: China Agricultural Science and Technology Press, 2018; 335p. (in Chinese)

[18] Li L L, Xue J, Xie R Z, Wang K R, Hou P, Zhang F L, et al. Effects of grain moisture content on mechanical grain harvesting quality of summer maize. Acta Agron Sin, 2018; 44: 1747-1754. (in Chinese)

[19] Wang K R, Li L L, Gao S, Wang Y Z, Huang Z F, Xie R Z, et al. A analysis of main quality index of corn harvesting with combine in China. Acta Agronomica Sinica, 2021; 47(12): 2440-2449. (in Chinese)

[20] Wiersma J, Allrich T. Grain harvest losses. 2005. www.smallgrains.org/ Techfile/Sept78.htm. Accessed on [2020-02-10].

[21] GB/T 21962-2008. Technical conditions of corn harvesting machinery. General Administration of Quality Supervision and Quarantine of China and China National Standardization Administration.

[22] Hou L Y, Wang K R, Wang Y Z, Li L L, Ming B, Xie R Z. In-field harvest loss of mechanically-harvested maize grain and affecting factors in China. Int J Agric \& Biol Eng, 2021; 14(1): 29-37.

[23] Shay C W, Ellis L V, Hires W G. Measuring and reducing corn harvesting losses. G-Agricultural Guides (University of Missouri-Columbia. Extension): $01290 . \quad 1983 . \quad$ Available: http://hdl.handle.net/ 10355/7257. Accessed on [2020-01-10].

[24] DB41/T 1409-2017 Technical specification for corn grain yield measurement on mechanical harvest grain. Issued by Quality and Technical Supervision Bureau of Henan Province, China, 2017.

[25] Sun H, Xin X, Lin J, Wang X, Jing X. Effect of temperature on optimum moisture content of stored maize seeds. Sci Agric Sin, 2004; 37: 656-662 (in Chinese)

[26] Li L L, Lei X P, Xie R Z, Wang K R, Hou P, Zhang F L, et al. Analysis of influential factors on mechanical grain harvest quality of summer maize. Sci Agric Sin, 2017; 50: 2044-2051. (in Chinese)

[27] Hansen R C, Berry M A, Keener H M, Gustafson R J. Current grain drying practices in Ohio. Appl Eng Agric, 1996; 12: 65-69.

[28] Li H Y, Wang Y H, Xue J, Xie R Z, Wang K R, Zhao R L, et al. Allocation of maize varieties according to temperature for use in mechanical kernel harvesting in Ningxia, China. Int J Agric \& Biol Eng, 2021; 14(1): 20-28.

[29] Huang Z F, Hou L Y, Xue J, Wang K R, Xie R Z, Hou P, et al. Improving harvest efficiency of maize varieties via accumulated temperature in a certain planting area. Int J Agric \& Biol Eng, 2021; 14(4): 175-181.

[30] Wang K, Li L, Lu Z, Gao S, Wang Y, Huang Z, et al. Mechanized grain harvesting quality of summer maize and its major influencing factors in Huanghuaihai region of China. Transactions of the CSAE, 2021; 37(7): 1-7. ( in Chinese)

[31] Wang H, Liao J, Wu L, Sun M, Ding M, Luo B, et al. Investigation report on quality and quality of imported corn. Sci Technol Commun Grain Oil Storage, 2013; 1: 31-33. (in Chinese)

[32] Shouse S C, Hurburgh J C R, Hanna H M, Petersen D. Farm energy: Improving corn drying efficiency. Agric Environ Extension Publ, 2011; $198 \mathrm{p}$.

[33] Paulsen M R, Hofing S, Hill L L D, Eckhoff S R. Corn quality characteristics for Japan markets. Appl Eng Agric, 1996; 12: 731-738.

[34] Mahmoud A R. Distribution of damage in maize combine cylinder and relationship between physico-rheological properties of shelled grain and damage. Ames: Iowa State University. PhD dissertation. Library, Iowa State University, Ames, Iowa, 1972; 215p.

[35] Wu P-C J. Factors affection Wisconsin breakage tester results on corn. Master`s thesis. Kansns State University, Manhattan, Kansas, 1987; 175p.

[36] Al-Jalil H F, Marley S J, Chowdhury M H. Laboratory studies of a low-damage corn-shelling machine. Transactions of the ASAE, 1980, 23(2): 278-283.

[37] Cavanaugh K J, Zehr B E, Nyquist W E, Hamaker B R, Crane P L. Responses to selection for endosperm hardness and associated changes in agronomic traits after four cycles of recurrent selection in maize. Crop Sci, 1995; 35: 745-748. 